\title{
Morphometric analysis of patella and patellar ligament: a cadaveric study to aid patellar tendon grafts
}

\author{
Ashwini Aithal Padur ${ }^{1} \cdot$ Naveen Kumar $^{1}$ (D) Melissa Glenda Lewis ${ }^{2} \cdot$ Varalakshmi Chandra Sekaran $^{3}$
}

Received: 14 May 2021 / Accepted: 9 September 2021 / Published online: 27 September 2021

(c) The Author(s) 2021

\begin{abstract}
Purpose Morphometric analysis of the patella and the patellar ligament is crucial in diagnosing and surgical corrections of knee injuries and patellofemoral joint disorders. Dimensions of the patella and the patellar ligament are frequently used in implant design and ACL reconstruction. This study aims to obtain detailed morphometric data on the patellar ligament and its localization based on gross anatomical dissections in the adult cadavers.

Methods The present study consisted of 50 lower limbs from formalin-fixed male adult cadavers aged about 70 years (45-85) belonging to the South Indian population. Total length of the quadriceps tendon, patellar height, patellar ligament height, proximal width, distal width and thickness of the patellar ligament were measured meticulously. Mean, standard deviation, median scores of each parameter were computed for groups using SPSS 16.0. Level of significance was considered as $p<0.05$. Wilcoxon signed-rank test was used to compare the various parameters on the right and left limbs. The relationships between all parameters were analyzed using Spearman's rank correlation test.

Results There was no statistically significant difference in the various measurements of the patella and patellar ligament between the right and left lower limbs. Patellar ligament length showed positive correlation with ligament thickness $(r=0.36$; $p=0.078$ for right limb and $r=0.33 ; p=0.104$ for left limb). Proximal width of ligament showed significant positive correlation with distal width ( $r=0.41 ; p=0.041$ for right limb and $r=0.54 ; p=0.006$ for left limb).

Conclusion This morphometric data and analysis might be fundamental in understanding various knee conditions in situ and necessary to orthopedic surgeons for successful planning and execution for ACL reconstruction using patellar ligament graft and other patellofemoral joint disorders.
\end{abstract}

Level of evidence I

Keywords Patella $\cdot$ Patellar tendon $\cdot$ Dimensions $\cdot$ Morphometric $\cdot$ Tendon graft

\section{Introduction}

The most common injury at the knee joint, especially in sportspeople, is a tear of the anterior cruciate ligament (ACL). The patellar ligament and quadriceps tendon are

Naveen Kumar

naveentonse@gmail.com

1 Department of Anatomy, Melaka Manipal Medical College (Manipal Campus), Manipal Academy of Higher Education (MAHE), Manipal, Karnataka 576104, India

2 Indian Institute of Public Health, Shillong, Meghalaya, India

3 Department of Community Medicine, Melaka Manipal Medical College (Manipal Campus), Manipal Academy of Higher Education (MAHE), Manipal, Karnataka, India commonly used as grafts for ACL reconstruction, surgical revision, and multi-ligament surgery to restore functional stability. The patella is the largest sesamoid bone in the body that develops within the tendon of the quadriceps femoris muscle and is found on the anterior surface of the femoral condyles. It has two surfaces (anterior and posterior), three borders (superior, medial, and lateral), and an apex pointing inferiorly [31]. The patella, also called a knee cap, does not have morphological sex determination; nevertheless, it is one of the few bones in the human body that is resistant to post-mortem changes [25]. The extensor mechanism of the knee consists of the quadriceps muscle group and tendon, the patella, the patellar ligament, the tibial condyles, and the patellar retinaculum [11]. The patellar tendon (patellar ligament) is the central band of the tendon of the quadriceps femoris, which is continued distally from the patella to the 
tibial tuberosity. It is strong, flat, about $6 \mathrm{~cm}$ in length, and is attached proximally to the patellar apex and adjoining margins, while distally, it is attached to the tibial tuberosity [31]. This insertion is oblique and directed laterally. In the procedure of tibial osteotomy, the tibia is cut transversely just above the patellar tendon insertion. Failure to appreciate the obliquity of the tibial attachment of the tendon may lead to an unintended division of the tendon during this procedure, leading to unfortunate consequences [31].

Morphometric data from the studies on the patella and patellar ligament are crucial in the diagnosis and surgical corrections of knee-related injuries [21,33] and patellofemoral joint disorders $[2,28]$. Dimensions of the patella and patellar ligament are frequently utilized in implant design and specific surgical procedures such as patella resurfacing for total knee arthroplasty and the harvesting technique of patellar ligament grafts during the reconstruction of the anterior cruciate ligament $[24,26]$. Determining the relationship between the patella and patellar ligament in different population groups is essential anthropologically and clinically. Understanding the pathogenesis of disorders involving the knee calls for detailed knowledge of the normal anatomy and biomechanics of the patella and the patellar ligament [9]. Previous studies have shown significant evidencebased racial differences in the morphometry of the knee joint, patellar ligament amongst the studied populations [8]. There are not any detailed studies dealing with the patella and patellar ligament morphometric measurements using cadavers belonging to the Indian population. The advantage of the measurements performed in a cadaveric approach is that they do not involve approximation and assumptions. Thus, in this study, we aimed to obtain detailed morphometric data on the patellar ligament and its localization based on gross anatomical dissections in the adult cadavers.

\section{Materials and methods}

The study sample consisted of 50 lower limbs (25 right lower limbs and 25 left lower limbs) from formalin-fixed ( $10 \%$ formalin) male cadavers belonging to the South
Indian population, procured from the Anatomy department of our college. The mean age of the cadavers was 75 years (45-85). Cadavers with osteoarthritic changes to the knee, visible surgical scars in the knee region, physical signs of deformity of the patella, or patellofemoral disease were excluded from the study. The incision was made on the medial sides of both knees of the cadaver, skin and facia lata were carefully removed to expose the quadriceps tendon, the patella, and the patellar ligament. The tendon of the quadriceps femoris and the patellar ligament was carefully freed from the underlying structures without causing any alteration to the desired structures. All measurements were performed while the patella and patellar ligament were in situ. The various morphometric measurements were measured using a calibrated rigid ruler (accuracy, $0.5 \mathrm{~mm}$ ) and silk suture thread. All measurements were taken twice, in the same manner by the same investigator for all the limbs to avoid interobserver variability. Since there was no differences in the measurements, intra-observer reliability test was not performed. Total length of the quadriceps tendon, patellar height, patellar ligament height (patellar tendon length), proximal width, distal width and thickness of the patellar ligament were measured meticulously. The description of the measurements is shown in Table 1 and Fig. 1.

The mean, standard deviation, median scores of each parameter were computed concerning groups using SPSS 16.0 statistical package (SPSS Inc, Chicago, IL). Level of significance ( $p$-value) was set at 0.05 . Wilcoxon signedrank test was used to compare the various parameters on right and left limbs. The relationships between all parameters were analyzed using Spearman's rank correlation test. To determine the statistical power, we performed power analysis for correlation in $\mathrm{R}$ version 3.6.3. The correlation power analysis estimated a power of $82.2 \%$ to determine the statistical power between the proximal width vs distal width in the left lower limb with a sample size of 25 , level of significance of $5 \%$ and correlation coefficient of 0.54 . Results were represented in relevant tables and graphs (Tables 2, 3, 4 and 5).

Table 1 Description of measurements taken of the patella and patellar ligament

\begin{tabular}{|c|c|c|}
\hline Measurement & Abbreviation & Description \\
\hline Total length & $\mathrm{TL}$ & $\begin{array}{l}\text { The linear distance between the base of the patella and the attachment of } \\
\text { the patellar ligament to the tibial tuberosity }\end{array}$ \\
\hline Patella height & $\mathrm{PH}$ & The linear distance between the superior border and the apex of the patella \\
\hline Patellar ligament height/patellar tendon length & PLH & The linear distance between the apex of the patella and the tibial tuberosity \\
\hline Patellar ligament width (proximal end) & PW & Maximum width of the ligament just below the apex of the patella \\
\hline Patellar ligament width (distal end) & DW & Maximum width of the ligament just above tibial tuberosity \\
\hline Patellar ligament thickness & PT & The thickness of the ligament above its distal attachment \\
\hline
\end{tabular}




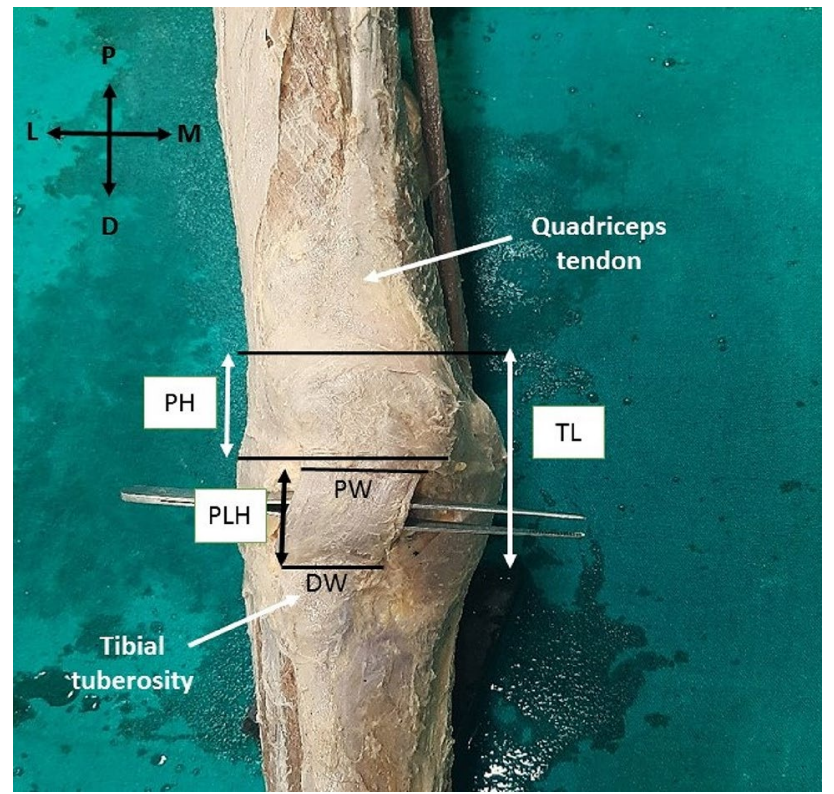

Fig. 1 Figure showing the various measurements of the patella and patellar ligament. $T L$ total length, $P H$ patella height, $P L H$ patellar ligament height, $P W$ patellar ligament width (proximal end), $D W$ patellar ligament width (distal end). Axis: $P$ proximal, $D$ distal, $M$ medial, $L$ lateral

\section{Results}

\section{Side differences}

A Wilcoxon signed-rank test showed that there was no statistically significant difference in the various measurements of the patella and patellar ligament between the right and left lower limbs $(p>0.05)$ (Fig. 2, Table 3). The average length of the patellar ligament was $4.8 \mathrm{~cm}$ on the right limb and $4.6 \mathrm{~cm}$ on the left limb. The shortest ligament was about $2 \mathrm{~cm}$ (range $3-6 \mathrm{~cm}$ ) was observed in the left limb with no obvious pathology. Patellar height was almost the same in both limbs $(5.03 \mathrm{~cm})$ (Table 3).

\section{Descriptive analyses}

The mean, standard deviation, and median scores for the measurements of the patella and the patellar ligament are presented in Table 2.

\section{Analyses of correlation}

Spearman's correlation analysis was performed.

Patellar ligament length showed low correlation with ligament thickness $(r=0.36 ; p=0.078$ for right limb and $r=0.33$; $p=0.104$ for left limb) (Table 4, Fig. 3). Proximal width of ligament showed significant positive correlation with distal width $(r=0.41 ; p=0.041$ for right limb and $r=0.54 ; p=0.006$ for left limb) (Table 5, Fig. 4). There was a negative $(r=-0.18)$ statistically non-significant ( $p$ value $=0.38$ ) relationship between patella height and patellar tendon length (PLH) in the right lower limb. However, in the left lower limb, there was a negative $(r=-0.47)$ statistically significant moderate $(p$ value $=0.02)$ relationship between patella height and patellar tendon length (PLH) in the right lower limb (Fig. 5). This indicates that, as the patellar height increases, the patellar tendon length decreases.

\section{Discussion}

A relevant anatomical knowledge regarding musculoskeletal structure with its associated relationships has always been essential to orthopedic surgeons. Although many studies focus on the geometry of patella and patellar tendon, these studies are mainly radiological, intraoperative measurements, and biomechanical studies. There are very few cadaveric studies dealing with the actual in situ measurements of the patella and patellar ligament to the authors' knowledge. Thus, this study was aimed to provide the whole integrated morphometry of the patella and patellar ligament using anatomical dissection. Although the anatomical methods have the disadvantage of limited clinical material for substantial clinical research, the data obtained from these studies are beneficial for adapting to modern surgical procedures.
Table 2 Table showing the various morphometric measurements of the patella and patellar ligament

\begin{tabular}{lllllll}
\hline Variables & \multicolumn{2}{l}{ Right lower limb } & & \multicolumn{2}{l}{ Left lower limb } & \\
\cline { 2 - 3 } & Median & Mean \pm SD $(\mathrm{cm})$ & & Median (range) & Mean \pm SD (cm) \\
\hline Total length (TL) & 10 & $9.96 \pm 0.84$ & & 10 & $9.88 \pm 0.88$ \\
Patellar height (PH) & 5 & $5.08 \pm 0.64$ & & 5 & $5.2 \pm 0.78$ \\
Patellar ligament height (PLH) & 5 & $4.88 \pm 0.65$ & & 5 & $4.68 \pm 0.91$ \\
Proximal width (PW) & 3.5 & $3.56 \pm 0.43$ & & 4 & $3.50 \pm 0.44$ \\
Distal width (DW) & 2.5 & $2.62 \pm 0.49$ & & 2.5 & $2.48 \pm 0.45$ \\
Patellar ligament thickness (PT) & 6 & $5.92 \pm 0.62$ & & 6 & $5.80 \pm 0.74$
\end{tabular}


Fig. 2 Comparison of morphometric measurements between right and left lower limbs

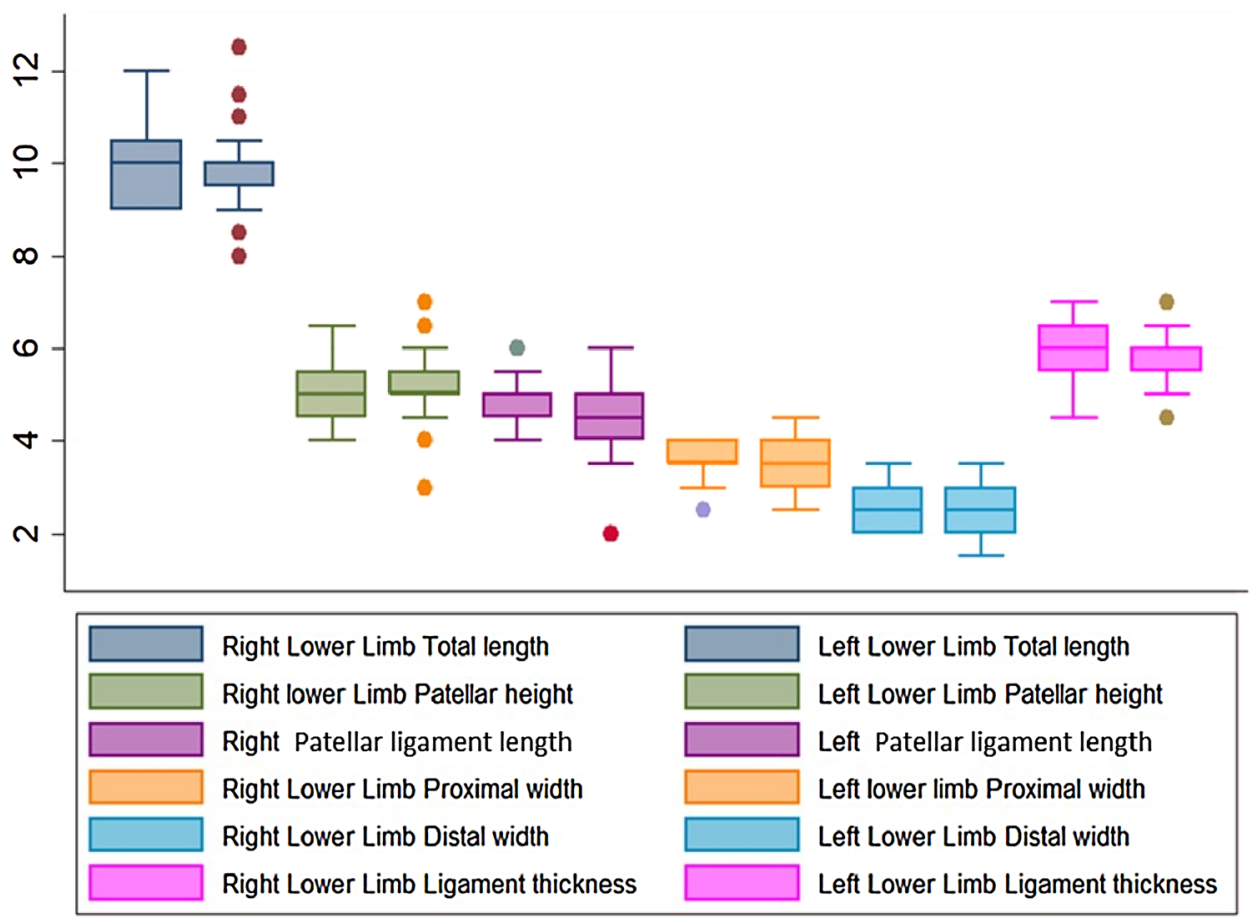

Table 3 Table showing the result for Wilcoxon signed-rank test to compare the level of significance between the studied variables in the right and left limbs

\begin{tabular}{ll}
\hline Wilcoxon Signed rank test & \\
\hline Variables & $\begin{array}{l}p \text {-value (between } \\
\text { right and left } \\
\text { limbs) }\end{array}$ \\
\hline Total length (TL) & 0.664 \\
Patellar height (PH) & 0.322 \\
Patellar ligament height (PLH) & 0.368 \\
Proximal width (PW) & 0.551 \\
Distal width (DW) & 0.3137 \\
Patellar ligament thickness (PT) & 0.4437 \\
\hline
\end{tabular}

Table 4 Table showing the correlation between the length of the patellar ligament and ligament thickness in the right and left lower limbs

\begin{tabular}{lll}
\hline $\begin{array}{l}\text { Length of patellar ligament vs } \\
\text { ligament thickness }\end{array}$ & $\begin{array}{l}\text { Spearman's rank correla- } \\
\text { tion coefficients }\end{array}$ & $p$-value \\
\hline Right lower limb & 0.36 & 0.078 \\
Left lower limb & 0.33 & 0.104 \\
\hline
\end{tabular}

Morphometric measurements of the patella are important anthropologically as they can be used in forensic science for sex determination with the highest accuracy rate. In the present study mean height of the patella was approx. $5 \mathrm{~cm}$ on both limbs. This finding is similar to the study of Schlenzka et al., wherein the mean patellar height was $5.4 \mathrm{~cm}$ in 50 fresh cadaveric patellae studied by them [28]. In previous studies, the mean patellar height was found to be $44.6 \mathrm{~mm}$ which was MRI study [33], $39.9 \mathrm{~mm}$ in a study on CT scans from 40 Chinese volunteers [30], $42.96 \mathrm{~mm}$ in a study using dry patella [4], $38.07 \mathrm{~mm}$ in a study on dry patella of Indian population [20], and $43.7 \mathrm{~mm}$ in cadaveric patellae of European ancestry [23]. Although the reasons for variations in patellar height cannot be validated, the differences may be due to the difference in methods of measuring, age, sexes, study group, ethnicity, and stature [23]. It is known that morphometric variations are often observed in measurements even within the same population group and that the variation could be more striking across different ethnic groups.

Dimensions and classification of patellae are important for anthropologists and surgeons for the determination of the size of a patellar implant [18]. A disproportional implant of the patellofemoral joint would result in ineffective lever support, limitation of motion, excessive wear, and patella instability with associated knee pain [14].

The development of the patellar ligament in the fetal period is important as the pathologic conditions of the patellar ligament in adulthood may be associated with fetal development [5, 19]. Patellar ligament plays a vital role in the extensor mechanism of knees, and patellar tendinitis, partial or complete ligament tears, can result in loss of ligament function. It is opined that complete patellar ligament tears are primarily seen in athletes, volleyball, and basketball players [10]. Ligament tear will result in restricted activity levels, thereby decreasing quality of life [16]. Hence knowledge regarding the exact anatomy of the patellar ligament is 

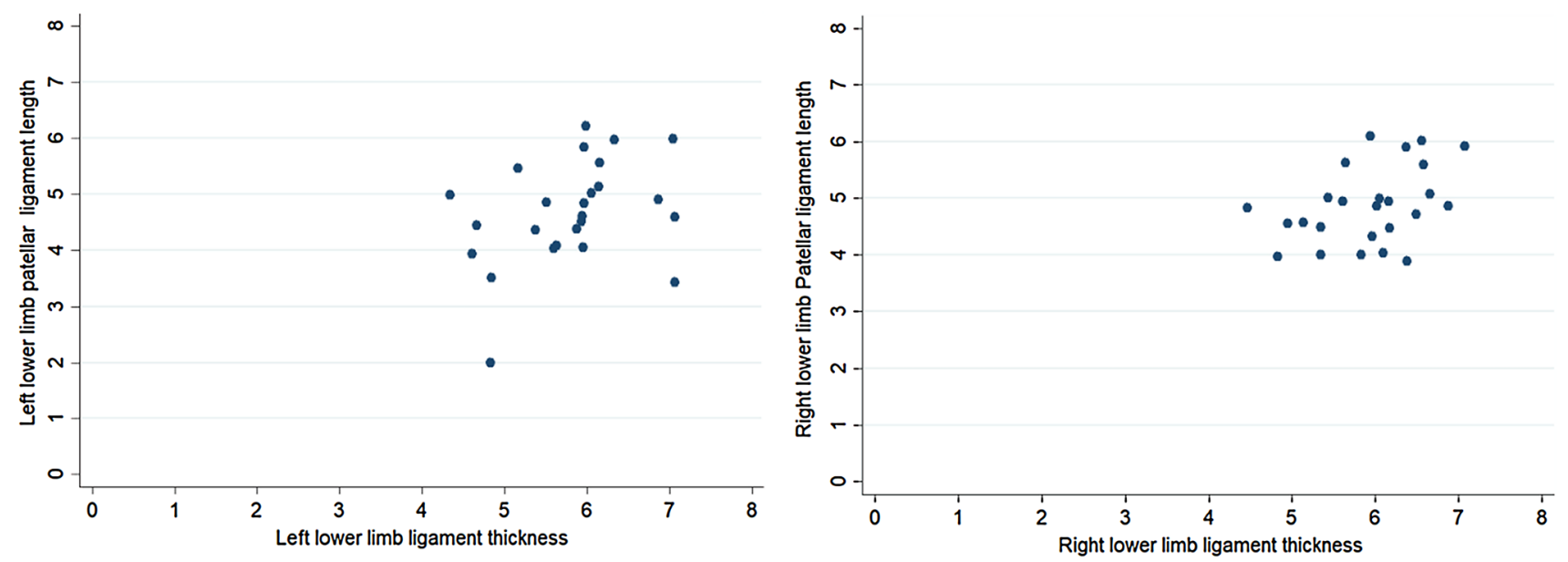

Fig. 3 Correlation between lengths of patellar ligament vs. ligament thickness in right and left lower limbs

Table 5 Table showing the correlation between proximal and distal width of the patellar ligament in the right and left lower limbs

Proximal width vs distal width Spearman's rank correla- $\quad p$-value of the patellar ligament tion coefficients

\begin{tabular}{lll}
\hline Right lower limb & 0.41 & $0.041^{*}$ \\
Left lower limb & 0.54 & $0.006^{*}$ \\
\hline
\end{tabular}

*At $5 \%$ level of significance

important to understand its functional mechanism and aid in its surgical reconstruction. Another common ligament injury seen nowadays is the tear of the anterior cruciate ligament (ACL). ACL is an intracapsular ligament of the knee joint. The area of origin and insertion of the ACL is reported to average 113 and $136 \mathrm{~mm}^{2}$, respectively. The cross-sectional area at midsubstance varies between 36 and $44 \mathrm{~mm}^{2}$, while the length of the anterior and posterior aspect of the ligament is reported to vary between 22 and $41 \mathrm{~mm}[7,12]$. With varying techniques employed by surgeons, the source of the graft tissue to replace the damaged ACL is of critical importance to ensure the best outcome. The most commonly used grafts for ACL reconstruction are those of the patellar ligament and the hamstrings (semitendinosus or gracilis), to a lesser extent, the fascia lata and quadriceps tendon [27]. Although there are numerous options available, there is no agreement in the literature on the most suitable choice for the graft source $[1,17,22]$. Many factors need to be considered in selecting a graft material like, it should be easily accessible, should rapidly ligamentize once implanted, and be comparable to the strength of ACL [13]. Therefore, the patellar ligament is the most favored choice for graft as it has greater tensile strength, it may be vascular, and can have some bony part with it providing better chances for
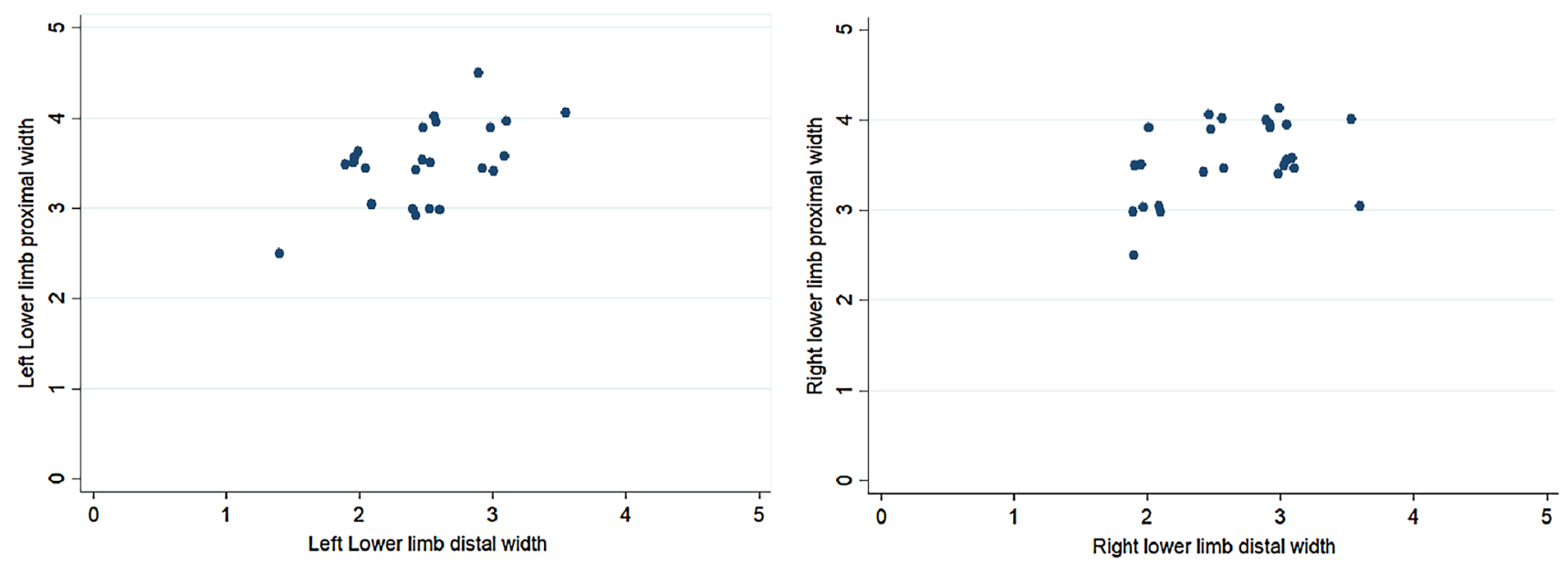

Fig. 4 Correlation between Proximal width vs. distal width of the patellar ligament between the right and left lower limbs 

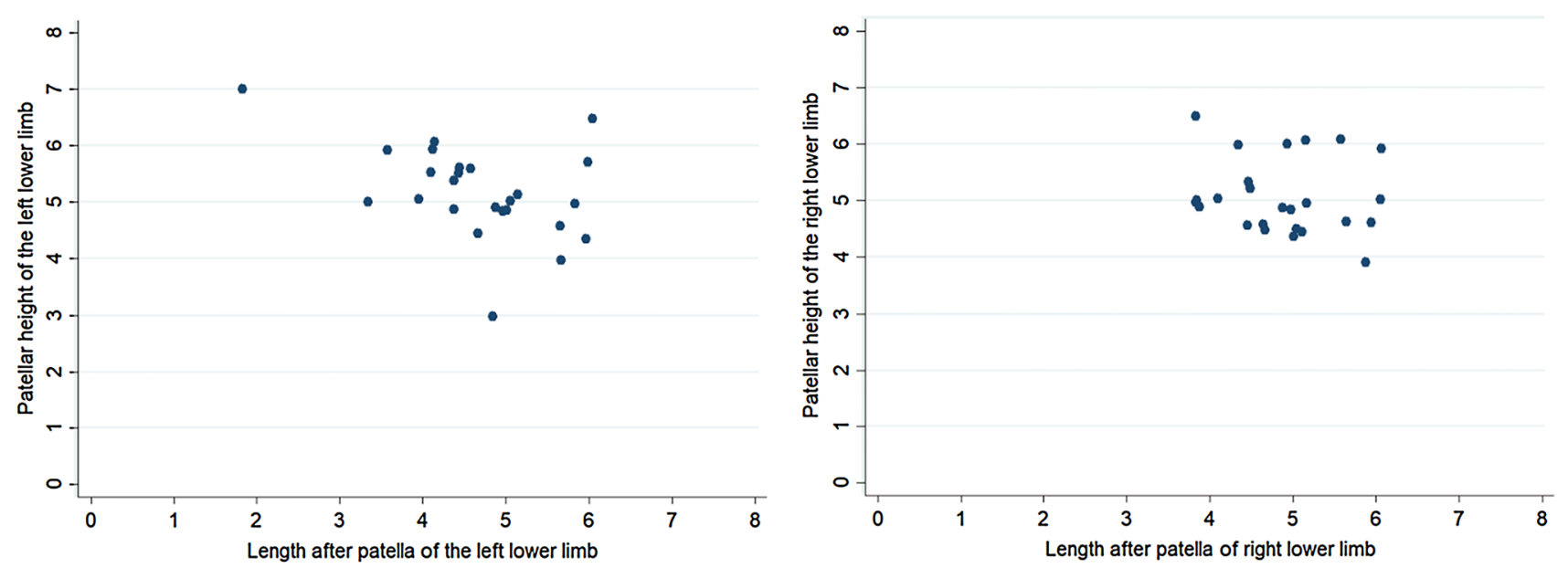

Fig. 5 Correlation between patellar height vs. length after patella (patellar ligament height) of the right and left lower limbs

successful graft [3]. Both the quadriceps tendons and patellar ligaments have been tested for strength and load-bearing capacity and are comparable in this regard [15]. The patellar ligament is stronger and more rigid than the quadriceps tendon [29]. Patellar tendon bone grafts should be used for young patients and high demand athletes who prefer early return to high-level activities, while hamstring tendons are advantageous when a large skin incision or anterior knee pain should be avoided [6]. The length of the patellar tendon is a major concern in ACL reconstruction surgery with a patellar tendon graft. The bone peg harvested from the inferior pole of the patella is usually placed at the femoral tunnel, and that from tibial tuberosity at the tibial tunnel, and the ligament substance between the bong pegs acts as the reconstructed ACL [33].

We found in our study that the length of the patellar ligament on the right limb was slightly more when compared to the left limb, and a slight positive correlation was observed between the ligament length and ligament thickness in both the limbs ( $r=0.36$ for right limb and $r=0.33$ for left limb). Even though we could not give exact justification for these observations, we assume that factors such as predominant use of one limb, posture, physique, etc., might produce better muscle tone on one side, thereby directly affecting the length and thickness of the patella and patellar ligament. A positive correlation was also observed between the proximal and distal width of the patellar ligament in both limbs $(r=0.41$ for right limb and $r=0.54$ for left limb). The patellar ligament was wider proximally than distally, which was following a previous study [32]. The authors opine that this difference is because the tendon fascicles tend to converge toward the midline before their attachment to the tibia. Although the measurements performed in a cadaveric approach is advantageous as they do not involve approximation and assumptions, the measurements obtained from images are more accurate and repeatable. A single technique is unlikely to be optimal in all circumstances. Therefore, we suggest that morphometric measurements from the cadaveric method and radiological methods could be integrated to provide optimum accuracy and desired reproducibility in clinical settings.

Limitations of the present study include the use of embalmed cadavers; the gender-wise difference could not be calculated due to the non-availability of female cadavers and the absence of data such as height or BMI of the cadavers. Although we found a correlation between patellar ligament length and thickness, we could not find detailed studies in the literature to correlate our findings and assumptions. Another limitation of the study was that, as two or more observers could not do the morphometric measurements, the inter-observer error of measurement could not be performed. Therefore the accuracy of measurements could not be reinforced.

\section{Conclusion}

The present cadaveric study is beneficial for local anthropological records and provides an essential reference guide for designing patellar prosthetic implants for the South Indian population. This morphometric data might be fundamental in understanding various knee conditions in situ and necessary to orthopedic surgeons for successful planning and execution for ACL reconstruction using patellar ligament graft and other patellofemoral joint disorders.

Author contributions Protocol/project development: AAP, NK. Data collection: AAP, NK. Data analysis: MGL, VCS. Manuscript writing/ 
editing: AAP, NK. All authors have read and approved the final version of the manuscript.

Funding Open access funding provided by Manipal Academy of Higher Education, Manipal. Nil.

Availability of data and material Data from human cadavers were used for the study.

Code availability Not applicable.

\section{Declarations}

\section{Conflict of interest None.}

Open Access This article is licensed under a Creative Commons Attribution 4.0 International License, which permits use, sharing, adaptation, distribution and reproduction in any medium or format, as long as you give appropriate credit to the original author(s) and the source, provide a link to the Creative Commons licence, and indicate if changes were made. The images or other third party material in this article are included in the article's Creative Commons licence, unless indicated otherwise in a credit line to the material. If material is not included in the article's Creative Commons licence and your intended use is not permitted by statutory regulation or exceeds the permitted use, you will need to obtain permission directly from the copyright holder. To view a copy of this licence, visit http://creativecommons.org/licenses/by/4.0/.

\section{References}

1. Anderson AF, Snyder RB, Lipscomb AB (2001) Anterior cruciate ligament reconstruction: a prospective randomized study of three surgical methods. Am J Sport Med 29:272-279

2. Andrikoula S, Tokis A, Vasiliadis HS, Georgoulis A (2006) The extensor mechanism of the knee joint: an anatomical study. Knee Surg Sports Traumatol Arthrosc 14:214-220

3. Butler DL, Grood ES, Noyes FR, Sodd AN (1985) On the interpretation of our anterior cruciate ligament data. Clin Orthop Relat Res 196:26-36

4. Chhaparwal R, Hiware S, Chhaparwal P, Chhaparwal N (2018) Morphometric study of knee cap (patella). Ann Int Med Dent Res 4(6):AT05-AT09

5. Chung CB, Skaf A, Roger B, Campos J, Stump X, Resnick D (2001) Patellar tendon lateral femoral condyle friction syndrome: MR imaging in 42 patients. Skelet Radiol 30(12):694-697

6. Dargel J, Gotter M, Mader K, Pennig D, Koebke J, SchmidtWiethoff R (2007) Biomechanics of the anterior cruciate ligament and implications for surgical reconstruction. Strateg Trauma Limb Reconstr 2(1):1-12

7. Duthon VB, Barea C, Abrassart S et al (2006) Anatomy of the anterior cruciate ligament. Knee Surg Sports Traumatol Arthrosc 14:204-213

8. Faraj AA, Nevelos AB (2000) Ethnic factors in Perthes disease: a retrospective study among white and Asian population living in the same environment. Acta Orthop Belg 66(3):255-258

9. Fox AJS, Wanivenhaus F, Rodeo SA (2012) The basic science of the patella: structure, composition, and function. J Knee Surg 25(2):127-141

10. Garau G, Rittweger J, Mallarias P, Longo UG, Maffulli N (2008) Traumatic patellar tendinopathy. Disabil Rehabil 30(20-22):1616-1620
11. Grelsamer RP, Weinstein $\mathrm{CH}$ (2001) Applied biomechanics of the patella. Clin Orthop Relat Res 389:9-14

12. Harner CD, Baek GH, Vogrin TM et al (1999) Quantitative analysis of anterior cruciate ligament insertions. Arthroscopy 15:741-749

13. Hijazi MM, Khan MA, Altaf FMN, Ahmed MR, Alkhushi AG, Sakran AMEA (2015) Quadriceps tendon and patellar ligament; a morphometric study. Prof Med J 22(9):1192-1195

14. Iranpour F, Merican AM, Cobb JP, Amis AA (2008) The width: thickness ratio of the patella: an aid in knee arthroplasty. Clin Orthop Relat Res 466:1198-1203

15. Jones KG (1970) Reconstruction of the ACL using the central one-third of the patellar ligaments. A follow up reports. J Bone Jt Surg (Am) 52A:1362-1368

16. Kadir D, Necdet K, Levent E, Hasan O (2014) Morphometry of the patellar ligament in human fetuses. SDU Typ Fak Derg 21(2):35-40

17. Keays SL, Bullock-Saxton J, Keays AC, Newcombe P (2001) Muscle strength and function before and after anterior cruciate ligament reconstruction using semitendinosus and gracilis. Knee 8:229-234

18. Koyuncu E, Cankara N, Sulak O, Ozguner G, Albay S (2011) The morphometry of patella and patellar ligament during the fetal period. Clin Anat 24:225-231

19. Lee D, Bouffard JA (2001) Ultrasound of the knee. Eur J Ultrasound 14(1):57-71

20. Murugan M, Ambika S, Nim VK (2017) Knee cap: a morphometric study. Int J Anat Res 5(1):3556-3559

21. Miller TT, Staron RB, Feldman F (1996) Patellar height on sagittal MR imaging of the knee. AJR Am J Roentgenol 167:339-341

22. Mologne TS, Friedman MJ (2000) Graft options for ACL reconstruction. Am J Orthop 29:845-853

23. Olateju OL, Philander I, Bidmos MA (2013) Morphometric analysis of the patella and patellar ligament of South Africans of European ancestry. S Afr J Sci 109(9/10):1-5

24. Philips CL, Silver DAT, Schranz PJ, Mandalia V (2010) The measurement of patellar height: a review of the methods of imaging. $\mathrm{J}$ Bone Jt Surg Br 92B:1045-1053

25. Phoophalee P, Prasitwattanaseree S, Riengrojpitak S, Mahakkanukrauh P (2012) Sex determination by patella measurement in Thais. In: Proceedings of the 1st ASEAN plus three graduate research congress, pp 472-477

26. Portner O, Pakzad H (2011) The evaluation of patellar height: a simple method. J Bone Jt Surg Am 93:73-80

27. Potage D, Duparc F, D'Utruy A, Courage O, Roussignol X (2015) Mapping the quadriceps tendon: an anatomic and morphometric study to guide tendon harvesting. Surg Radiol Anat 37(9): 1063-1067

28. Schlenzka D, Schwesinger G (1990) The height of the patella: an anatomical study. Eur J Radiol 11:19-21

29. Shaieb MD, Kan DM, Chang SK, Marumoto JM, Richardson AB (2002) A prospective randomized comparison of patellar tendon verses semitendinosus and gracilis tendon autografts for anterior cruciate ligament reconstruction. Am J Sports Med 30:214-220

30. Shang P, Zhang L, Hou Z, Bai X, Ye X, Xu Z, Huang X (2014) Morphometric measurement of the patella on 3D model reconstructed from CT scan images for the southern Chinese population. Chin Med J 127:96-101

31. Standring S (2008) Upper arm. In: Gray's anatomy, 40th edn. Elsevier Churchill Livingstone, Edinburgh, pp 1394-1396

32. Toumi H, Higashiyama I, Suzuki D, Kumai T, Bydder G, McGonagle D, Emery P, Fairclough J, Benjamin M (2006) Regional variations in human patellar trabecular architecture and the structure of the proximal patellar tendon enthesis. J Anat 208(1):47-57 
33. Yoo JH, Yi SR, Kim JH (2007) The geometry of patella and patellar tendon measured on knee MRI. Surg Radiol Anat 29(8):623-628
Publisher's Note Springer Nature remains neutral with regard to jurisdictional claims in published maps and institutional affiliations. 